| Volume-1 | Issue-1 | Jul-Aug 2019 |

Original Research Article

\title{
Comparative Study of English Proficiency Tests
}

\author{
Yan Chen* \\ China University of Political Science and Law, 27 Fuxue Lu, Changping District, Beijing, China \\ *Corresponding Author \\ Yan Chen
}

Article History

Received: 25.07 .2019

Accepted: 13.08 .2019

Published: 30.08 .2019

\begin{abstract}
English proficiency test is one of the most authoritative types of language competence test, which can measure English competence of test-takers accurately. The validity and reliability of English proficiency test are relatively authoritative. The results of test are the authentic representation of test-takers' level. Since English are spread and used widely all over the world, different kinds of English proficiency tests appear rapidly. Recently, College English Test (CET), Test of English as a Foreign Language (TOEFL) and International English Language Testing System (IELTS) are representative sample for English proficiency test in China. This dissertation compares CET with TOEFL and IELTS by summarizing their test forms and contents in listening, reading, writing and speaking, and analyzes features and purposes of CET, TOEFL and IELTS. According to the systemic analysis, this dissertation brings up the proper attitude that test-takers should hold for English proficiency test. Meanwhile, the author proposes some effective methods of English study for English proficiency test. The author also makes some rational suggestions for developing college English teaching method and modes of instruction.
\end{abstract}

Keywords: English proficiency test; TOEFL; IELTS; washback effect.

\section{INTRODUCTION}

\section{Research background}

Testing is one of the most important methods of language teaching, and it is also the main method to measure a person's language ability. In recent years, language testing becomes more significant to many people and organizations.

Language testing is an individual subject. According to different purpose of tests, it can be classified into six types, which are Aptitude Tests, Proficiency Tests, Achievement Tests, Diagnostic Tests, Structural Tests and Communicative Tests. The validity and reliability of tests are the main foundations to determine whether the tests are successful.

Reliability is treated as "the actual level of agreement between the results of one test with itself or with another test". "Reliability is a necessary condition for it, in the sense that test scores that are not reliable cannot provide a basis for valid interpretation and use [1]".

Bachman defines validity as following;

Validity is an integrated evaluative judgment of the degree to which empirical evidence and theoretical rationales support the adequacy and appropriateness of inferences and actions based on test scores or other modes of assessment [1].

\section{Research purpose}

English proficiency tests mainly examine test-takers about the degree of English. Proficiency Tests are not based on any particular English materials. They focus on integral language proficiency of test-takers. There are several English proficiency tests which are authoritative and formal, such as the TOEFL (Test of English as a Foreign Language), GRE (Graduate Record Examinations) of ETS [4], the BEC (Business English Certificate) of UCLES (University of Cambridge Local Examinations

Copyright @ 2019: This is an open-access article distributed under the terms of the Creative Commons Attribution license which permits unrestricted use, distribution, and reproduction in any medium for non commercial use (NonCommercial, or CC-BY-NC) provided the original author and source are credited. 
Syndicate)[5], LCCI (London Chamber of Commerce and Industry), CET-4 (College English Test Band 4), CET-6 (College English Test Band 6), TEM-4 (Test for English Majors 4) and TEM-8 (Test for English Majors 8).

As the scores of English proficiency test can clearly show test-takers' degree of English, the certificate of English proficiency test have become an important requirement for more and more organization. College students need CET-4 to receive bachelor degree in Chinese, students who want to study abroad need TOEFL or IELTS score, and some companies may require BEC certificate when recruiting employees.

All these facts mean that English proficiency test plays a significant role in people's academic and social life. Therefore, it is considerable for people to know what English proficiency test is, How English proficiency test works, and what test-takers can do to pointedly study for those English proficiency tests.

\section{Research questions}

There are hundreds of English proficiency tests nowadays that people can take. Most of them are scientific, well-directed, comparable and operable.

This dissertation mainly discusses the question that what English proficiency test is and how to study English pointedly for taking English proficiency test.

English proficiency tests are treated as one of the most authoritative tests that people can take nowadays. Most of Chinese enterprises require employees passing the CET-4 or CET-6 examinations. American universities or colleges take scores of TOEFL as their requirements for entrances. Scores of English proficiency test have become a representation of a person's English proficiency. Therefore, by understanding what English proficiency test is, people can get a better idea about why they should take Proficiency Test, and what kind of Proficiency Test they should take.

\section{Significance of the study}

Some people still doubt that Language testing is an individual subject. They regard language testing as setting an examination paper and giving a mark. It is easy for people to set examination questions, but it is really hard to set them scientifically, accurately and equitably. As an individual subject, Language testing has specific research area and method. Language testing obtains scientific content from Linguistics, language teaching method and learning theory. Therefore, it is necessary to research Language testing systematically.

Most of English language testing that Chinese people take are Achievement Test in academic period. This kind of English language testing focuses on testing knowledge of specific subject. The testing is based on contents of concrete course. The midterm examination and final examination are typical Achievement tests. As English proficiency test becoming popular and considerable, it is important for people to understand what English proficiency test is and how to study English pointedly.

\section{Layout of the dissertation}

Firstly, this dissertation is trying to explain what English proficiency test is and what the features of English proficiency test are. This is the basic and main thesis of this dissertation, and it is also the theoretical basis of this dissertation.

Secondly, this dissertation choose two of the most authoritative English proficiency test as example to analyze what the purpose of those English proficiency test is, how those English proficiency tests being set and the reason of setting in that way. This dissertation chooses TOEFL and IELTS as example, tries to analyze these two typical English proficiency tests and finds their purposes and features.

Thirdly, this dissertation generalizes the main features of those English proficiency tests by distinguishing those English proficiency tests from other tests that Chinese students take frequently. CET-4 and CET- 6 are the general tests that Chinese college students take. TOEFL, IELTS and CET are all English proficiency tests, but there are still lots of differences between them. By comparing them, it can help people comprehend TOEFL and IELTS more accurate.

Finally, this dissertation summarizes some practical and effective methods of preparing those English proficiency tests. The ultimate purpose of this researching is to apply theory to practice.

After analyzing all the theories and examples of English proficiency test, the researching tries to help English learners apply those theories to practices and tests.

\section{LITERATURE REVIEW \\ English proficiency test}

In language testing situation, when a test-taker aimed to test global competence in a language, then the test-taker was, in conventional terminology, testing proficiency [2]. The proficiency test is intended to evaluate the language competence of test-takers, 
and to analyze whether the test-taker meet a prescribed standard. The purpose of proficiency tests is to "measure people's ability in a language regardless of any training they may have had in that language [3]".

\section{What Is English proficiency test}

English proficiency test is required construct validity and empirical validity by society, which means that the result of English proficiency test must offer the most realistic circumstances of test-takers and help to select talented persons. This kind of impetus and the development of Language testing theory cause the testing setters improving the testing.

\section{The Features of English proficiency test}

English proficiency test pays more attention on communicative competence. The forms of testing are various and authentic.

\section{Test of English as a Foreign Language}

The Test of English as a Foreign Language (TOEFL) is an authoritative English proficiency test which is hold by Educational Testing Service (ETS) since 1963. The official website of ETS defines TOEFL as follows;

As one of the most authoritative English proficiency test, The Test of English as a Foreign Language (TOEFL) is designed to measure the English proficiency of people whose native language is not English. Colleges and universities in the United States and Canada require TOEFL test scores from their international applicants. Academic institutions in other countries, as well as certain independent organizations, agencies, and foreign governments, have also found the test scores useful. (http://www.ets.org/toefl/ibt/about/)

There are nearly a million of people take TOEFL to represent their English proficiency every year. The total number of people who used to take TOEFL all over the world is more then 25 million. "The average English skill level ranges between Intermediate and Advanced." (http://www.ets.org/toefl/ibt/about/) The administration of TOEFL program is Education Testing Service (ETS). TOEFL offers three formats of test. They are computer-based, paper-based and Internet-based. Since the Internet-based test of TOEFL is more convenient, most of people take it as their first choose of test form.

The TOEFL test is a norm-referenced proficiency test [1]. The Test of English as a Foreign Language (TOEFL) focus on effective communication of English, but not single skills of language.

\section{International English Language Testing System}

"IELTS is the International English Language Testing System. It measures ability to communicate in English across all four language skills - listening, reading, writing and speaking - for people who intend to study or work where English is the language of communication." (http://www.chinaielts.org/en/about_ielts/index.shtml) It is developed by The University of Cambridge Local Examination Syndicate (UCLES), The British Council and IDP Education Australia.

The principle of IELTS is "to provide a secure, global, authentic and customer-focused test which measures true to life ability to communicate in English." (http://www.chinaielts.org/en/about_ielts/index.shtml). Many universities, colleges, governments, institutions and companies all over the world treat scores of IELTS as valid and authoritative representation of English proficiency to communicate with English speakers. There are over one million of people who have taken IELTS. The test is hold in 120 countries every year. IELTS "sets the standard in integrity, research and innovation" (http://www.chinaielts.org/en/about_ielts/index.shtml).

\section{Comparison of CET and TOEFL, IELTS}

CET-4 and CET-6 are one of the most conversant English proficiency tests which college students can take. By comparing CET with TOEFL and IELTS, it can help people to know better about what features of TOEFL and IELTS are, and how to response English proficiency test.

\section{Comparison of listening}

The ability of listening is a major part of language application. It is not only an important method of receiving information, but also a significant way of learning language. In addition, ability of listening is helpful to develop ability of reading, speaking and writing.

Listening teat mainly measures test-takers' ability of gaining oral information. The essence of language is to transmit and communicate. The purpose of listening test is to measure ability of acquiring knowledge by using language. This purpose determines that the method of listening test and listening materials are real, which means patterns, selections and questions of test must reflect listening and understanding process of actual communication.

The dialogues of CET are usually from parts of daily life. The structures and contents of dialogues are simple, and materials are always from familiar stories, speaking or statements. Since 1999 to 2006, there are 300 dialogues and 90 short listening materials. After analyzing short listening materials of CET-4, 31\% of listening materials are argumentation, $42 \%$ are narrations, and $27 \%$ are expositions. 
There are totally four parts of IELTS listening. The previous two parts are about daily life, social circumstances or different relationships. The following two parts are mainly educational, academic or global investigations or statements. The first part is dialogue between two people, and contents are social or informal, such as traveling arrangement, registering courses or visiting new cities. The second part is monologue about common and interesting topics, such as statement about entering school library. The third part always is discussion of academic topics between four students. The last part is a passage of speech or statement. IELTS listening materials are mainly about daily life and social culture, the type of literature are statement and discussion.

TOEFL listening test includes two dialogues and four speeches. The materials focus on school life, and contents are mainly from professors' lectures and conversations between teachers and students.

It shows that TOEFL and IETLTS emphasize truth and diversification of materials. Diversification of materials is reflected in types, topics and also ways of pronunciation. The materials of CET lack of truth. Those materials are not from real conditions, and most of them are modified.

\section{Comparison of reading}

CET has four passages of reading. The topics involve science, biography, social custom, culture, economy, education and history. The types of literature include narration, description, exposition and argumentation.

TOEFL has three passages in its reading part. There are 650 to 750 words in one passage. The topics involve history, science, commerce, education, social science, literature and art, engineering technology, sports and entertainment.

IELTS general reading includes social survival, training survival and general reading. The two passages of first part are related to daily life, always advertisements, notices, and posters from newspapers, magazines. The second part is two passages of training about language or technology. The third part is one advising or demonstrative passage about recent hot topic.

IELTS pay attention to test-taker' reading ability for living in English-speaking countries. TOEFL mainly focus on reading ability for studying in English-speaking countries. The main sources of CET reading materials are from newspapers or journals. CET regards criterion and technique as key points of selecting passages. Therefore, the materials about computer technology, biology and medical science appear a lot. It leads that some test-takers may be familiar with those topics than others, which means the validity of CET is reduced.

\section{Comparison of writing}

Writing part of CET requires test-takers to write a 100 to 120 words article in 30 minutes. The topics involve daily life and general knowledge. The form of test concentrates on diagram description and persuasive essay. CET writing test requires test-takers to express clearly, smoothly and correctly.

TOEFL writing test is more complicated than CET. It includes two parts, which are independent writing and writing based on listening material. Independent writing requires knowledge, experience, explanation and opinion for one topic. The effective response is a 300 words article. The writing based on listening material asks test-takers to read an academic article first, and then listen to a speech. By analyzing key points of listening and comparing them with the article, test-takers are asked to write a 150 to 225 words article.

General training writing of IELTS has two parts. The previous part usually requires test-takers to write a letter about the given topic. The letter must involve explanation for specific conditions, necessary contents, and correct form of letter. The following part asks test-takers to write an essay or a report, including several items such as basic information, solution for specific problem, expression or support of an idea. The themes are various, including government, environment, scientific technology, media, crime, culture and animal.

The writing tests of TOEFL and IELTS emphasize various form of writing. They measure test-takers' composite ability of writing, and try to offer a complete and real condition for test-takers to write. The writing test of CET also notices various form of writing, but it still requires three paragraphs form of writing. It limits thought of test-takers, and cannot represent real writing capability of test-takers.

\section{Comparison of speaking}

CET does not have speaking test. It is complemented by College Oral English Test, and can only be taken by test-takers who passed CET over specific scores. It means that there are only a small group of people can take it.

In speaking test of TOEFL, test-takers is required recording their responses by computer. The first two parts ask test-takers express their opinions for the given topics. The third and fourth parts need test-taker reading an article first, and then listening a 
dialogue or lecture. After reading and listening, test-takers are requested to answer related questions. In the fifth and sixth parts, testtakers should listen to a section of dialogue or lecture, and then answer questions. Test-takers can take notes to remember emphasis. The test focuses on quality, completeness and accurateness of responses.

Test-takers will have a meeting with their examiner in IELTS speaking test. The themes of conversation are usually oral and daily using. It always tests in a relaxing condition. In meeting section, questions are related with test-takers' families, jobs, educational backgrounds and habits. In second section, examiner usually asks contents that test-takers writing in their resume, such as culture or living backgrounds of test-takers. In the third section, test-takers are asked to talk about a topic from one question card. The next section is related to the third section, but the topic is more abstract. The last one or two minutes, examiner will discuss test-takers future plans.

Speaking is an essential part in TOEFL and IELTS, but not in CET. The speaking test of CET sets limitation for people. It reduces activities of test-takers to practice their oral English. By analyzing the form of tests, CET and IELTS both measure test-takers by people. The advantage is to comprehend test-takers' oral ability intuitively, but it also causes that validity may be affected by external factors, such as examiner's weariness or test-takers' nervousness. TOEFL speaking test is by the way of electronic network. It can help to improve objectivity and validity of scores, and also give attention to listening test.

\section{Improvement of performance on English proficiency test}

Many experts have studied the washback or backwash effect of English proficiency test. People ignore that essential purpose of proficiency test is to measure linguistic competence of test-takers, and only treat test as purpose of English study.

\section{The purpose of English proficiency test}

The main purpose of TOEFL is to measure whether linguistic competence of test-takers can reach the level of living and studying abroad. It offers a foundation for universities and colleges to select students based on their linguistic competence. The main purpose of IELTS is to provide levels of test-takers who want to study abroad or emigration. Therefore, TOEFL and IELTS have feature of selection. Nevertheless, the score of TOEFL and IELTS is not the only qualification for entering universities or emigration. It is a condition for level of language competence. It aims to measure test-takers English proficiency and it always center on language.

TOEFL and IELTS integrate tests of listening, reading, speaking and writing. Especially for TOEFL, it combines those four sections to test synthesized English ability. This kind of test is more closed to real life, and makes the result of test more valid and reliable.

\section{Effective methods of English study for English proficiency test}

Since the purpose of FOEFL and IELTS is to measure English language proficiency of test-takers, it is important for testtakers to regard study for English proficiency test as a preparation for their future abroad study or living. The scores of test is a representation of English competence. It is a result but not a reason of studying English. Therefore, the pointed study for English proficiency test aims to study English preferably, but not to get higher scores of test.

\section{Authentic listening}

Listening is the first step of communicating with people. Therefore, most of English proficiency tests emphasize to investigate listening competence.

The listening section of FOEFL and IELTS is the most important part of the whole test. For example, the investigation of listening is not limited in listening section. In TOEFL test, reading and speaking sections also require listening competence of testtakers.

The materials of listening may give by different people who use different accents. It is important for students to be familiar with general accents of English speakers, such as British accent or American accent.

The materials are from real life. If students are familiar with the settled conditions, it will be much easier for students to understand the whole materials in the test. Therefore, during the study of English, students should listen to materials which are speaking by native speakers. The materials can be from lectures, speeches, even movies and series. This kind of practice can help students conversant with materials in test.

\section{Massive reading}

Vocabulary is a significant part of English. It is pretty obvious in the reading test. FOEFL and IELTS require 6,000 to 8,000 words of vocabulary. The topics of articles in the test always involve history, science, commerce, education, social science, literature and art, engineering technology, sports and entertainment. Most of them are especially professional and technical. Without the large number of vocabulary, it is hard for students to understand the meaning of articles, not to mention to response questions. 
Not only enlarging vocabulary, learning how to read rapidly and correctly is also a necessary skill. Students can select reports and articles from serious publications such as Time, The Economist, Times and Washington Post. They are very similar with the articles from real tests. Students may feel severe at beginning, but it can help to increase English reading competence, which helps in proficiency test and following abroad study. Another effective method in English study is scanning read. It is practically used in English study and tests.

\section{Imitation for writing}

In writing section, various structures of sentences and adept range of vocabulary is one of the marking criteria. This standard emphasizes the importance of vocabulary. Because students are not native English speakers, it is easy for them write in the way that they speak Chinese. Reading reports and articles from serious publications is effective for practicing both reading and writing When reading an article, students can also imitate it to learn how to write in native way.

\section{Content-oriented speaking}

The basic requirement of speaking section is: (1) expressing the contents smoothly, correctly, completely with necessary supports and examples; (2) ranging words and grammars skillfully; (3) announcing clearly and affluently.

It means students should be used to think in English and express in English. The speaking test does not pay much attention to contents, but attach importance to the way and accent of speaking.

\section{CONCLUSION}

English proficiency test is one of the most authoritative tests for measuring English language proficiency. It is widely regarded as certification of English competence. More and more Chinese of all age want to take English proficiency test to prove their English proficiency, especially for Chinese college students. Because of disadvantages of college English teaching methods, it is still a large number of students treat English as a subject they need to learn. Since most of English proficiency test regard English as a practical skill that people need when they are living in an English-speaking country, it is difficult for people to get satisfied scores in authoritative English proficiency test such as TOEFL or IELTS. Those tests are based on communicative language test theory, and materials of tests originate from real life. For example, by combining reality of college English teaching, students should be encouraged to read original edition of articles that related to their major. It helps students to improve their understanding of reading. Colleges have made significant improvements in college English teaching. However, the existing Chinese English teaching system still presence a lot of disadvantages and how to solve these problems still remains unknown. How to change the rigescent method of English teaching, how to encourage activity of studying English, how to set proper attitude of studying English for proficiency test, are still there begging the answers.

\section{REFERENCE}

1. Bachman, L. F. (1990). Fundamental considerations in language testing. Oxford university press.

2. Brown, H. D. (2003). Principles of language learning and teaching. Beijing: Beijing Foreign Language Teaching and Research Press.

3. Hughes, A. (2002). Testing for language teachers. Beijing: Beijing Foreign Language Teaching and Research Press.

4. Educational Testing Service (ETS). <http://www.ets.org/toefl/ibt/about/>.

5. The University of Cambridge Local Examination Syndicate (UCLES). <http://www.chinaielts.org/en/about_ielts/index.shtml>. 